\title{
Device Embolization
}

National Cancer Institute

\section{Source}

National Cancer Institute. Device Embolization. NCI Thesaurus. Code C111642.

Movement of a medical device to an unintended location within the body with resulting obstruction of an organ or vessel. 